\title{
Simulation on metro railway induced vibration. Part II: effect of corrugated rail
}

\author{
Hougui Zhang ${ }^{1}$, Zhou Ren ${ }^{2}$, Qiong Wu ${ }^{3}$, Jie Yang ${ }^{4}$ \\ ${ }_{1,3,4}$ Beijing Municipal Institute of Labour Protection, Beijing 100054, China \\ ${ }^{2}$ Beijing Jiaotong University, Beijing 100044, China \\ ${ }^{1}$ Corresponding author \\ E-mail:108115261@bjtu.edu.cn, ${ }^{2} 13130708 @ b j t u . e d u . c n,{ }^{3} 18600053885 @ 163 . c o m,{ }^{4} J Y 121 @ 163 . c o m$
}

Received 1 November 2019; accepted 7 November 2019

DOI https://doi.org/10.21595/vp.2019.21154

Check for updates

Copyright $(C) 2019$ Hougui Zhang, et al. This is an open access article distributed under the Creative Commons Attribution License, which permits unrestricted use, distribution, and reproduction in any medium, provided the original work is properly cited.

\begin{abstract}
The deterioration of running surface, including out-of-round wheels and corrugated rails. The effect of out-of-round wheels on simulation of rail dynamic behavior was presented in a companion paper [1]. In this paper, the effect of corrugated rails was discussed. Considering a perfect round wheels moving on different irregularities rail surface, including perfect smooth rail, irregularities generated from a US PSD, measurement data from corrugated rails. Calculation result indicated that (1) the traditional used irregularity generated from US-PSD would not satisfy the requirement simulation on rolling noise and vibration generation in high frequency range; (2) corrugated rail plays the dominant role on the vibration which obviously related to its typical wavelength.
\end{abstract}

Keywords: railway induced vibration, corrugated rail, and acoustic roughness.

\section{Introduction}

The deterioration of running surface, including out-of-round wheels and corrugated rails, as which typical wavelength less than $1000 \mathrm{~mm}$, is also defined as 'acoustic roughness'. In order to distinguish the contribution of running surface deterioration by wheels and rail respectively, out-of-round wheels moving on perfect smooth rail surface in different train speeds had already discussed in a companion paper [1].

Were different from out-of-round wheels that were commonly neglected in modeling, track irregularities play an important role on nearly all of the calculation models as the excitation element. When modeling the dynamic stability of train running, calculating the substructures subjected to the moving loads from railway trains [2-4], and so on, it would be sufficient using irregularities which was simplify generated from functions of power spectrum density (PSD) summarized from US or Germany railway main lines. However, it should be figured out that the wavelength of US-PSD was scoped from $1.524 \mathrm{~m}$ to $304.8 \mathrm{~m}$, which highest effected frequency would be about $11 \mathrm{~Hz}$ when the train's speed at $60 \mathrm{~km} / \mathrm{h}$. Obviously, the common used track irregularities would not satisfy the requirement simulation on rolling noise and vibration generation, which interested frequency would be up to $80 \mathrm{~Hz}, 250 \mathrm{~Hz}$ [5, 6], and even $4000 \mathrm{~Hz}$.

Rail corrugation is a periodic deterioration on running surface of rail (Fig. 2). Measurement data shows rail corrugation lead to 15 to $20 \mathrm{~dB}$ (A) pass-by noise increasing than normal condition. The enlarged vibration and boring squeal noise are complained by the resident living nearby, metro passengers and even the metro train drivers [7].

In this paper, the effect of rail roughness on the simulation modeling was discussed, considering a perfect round wheels moving on different irregularities rail surface, including perfect smooth rail, irregularities generated from a US PSD, measurement data from corrugated rails.

\section{Irregularities input data}

The SIMPACK-ABQUES simulation model was presented in the companion paper [1]. As the 
only alternating quantity, the input wheel-rail interaction irregularities were introduced in this section.

\subsection{Traditional used irregularities}

Generally, it would be sufficient using irregularities which was simplify generated from US-PSD. In this paper, the Level 6 irregularity was generated in default SIMPACK package, using Eq. (1) and Table 1 parameters:

$S_{v}(\Omega)=\frac{k A_{v} \Omega_{c}{ }^{2}}{\Omega^{2}\left(\Omega^{2}+\Omega_{c}{ }^{2}\right)}$.

And the final irregularities were shown in Fig. 1.

Table 1. US-PSD track irregularity spectrum parameters

\begin{tabular}{|c|c|c|c|c|}
\hline$\Omega_{c} \mathrm{rad} / \mathrm{m}$ & $\Omega_{S} \mathrm{rad} / \mathrm{m}$ & $A_{a} \mathrm{~cm}^{2} \cdot \mathrm{rad} / \mathrm{m}$ & $A_{v} \mathrm{~cm}^{2} \cdot \mathrm{rad} / \mathrm{m}$ & Train speed $(\mathrm{km} / \mathrm{h})$ \\
\hline 0.8245 & 0.4380 & 0.0339 & 0.0339 & 60 \\
\hline
\end{tabular}
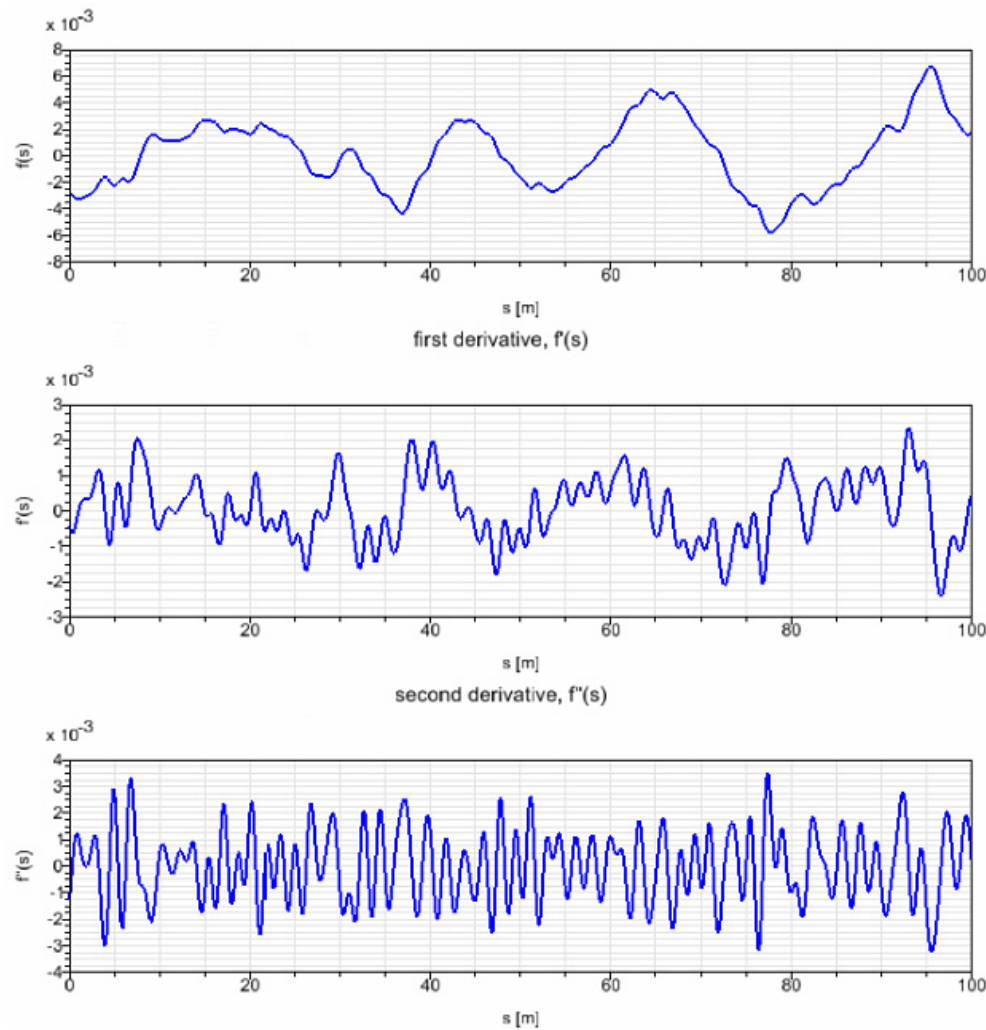

Fig. 1. Irregularities generated from US-PDF Level 6

\subsection{Roughness from measured data for corrugated rail}

For the corrugated rail, the roughness was measured using a corrugation analysis trolley (CAT) (Fig. 1). It is a hand operated device for measurement of longitudinal rail irregularities in the wavelength range from approximately $10 \mathrm{~mm}$ to $3,000 \mathrm{~mm}$. Rail irregularities are determined by integrating the signal from a vertical accelerometer mounted on a hard steel ball which rolls on 
the rail. Another wheel with rubber coating is used to determine the longitudinal position of the trolley and to trigger the samples. The sampling distance was $1 \mathrm{~mm}$. The data acquisition hardware was connected to a PC via a USB interface [8].

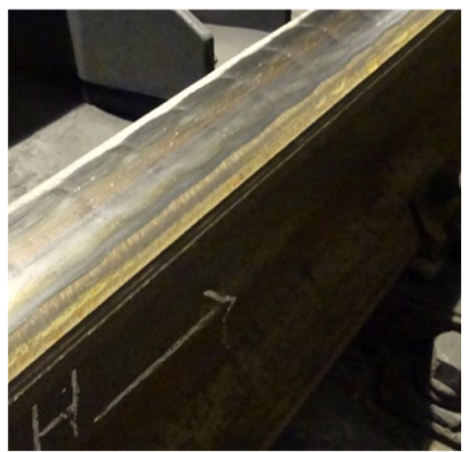

Fig. 2. Corrugated rail

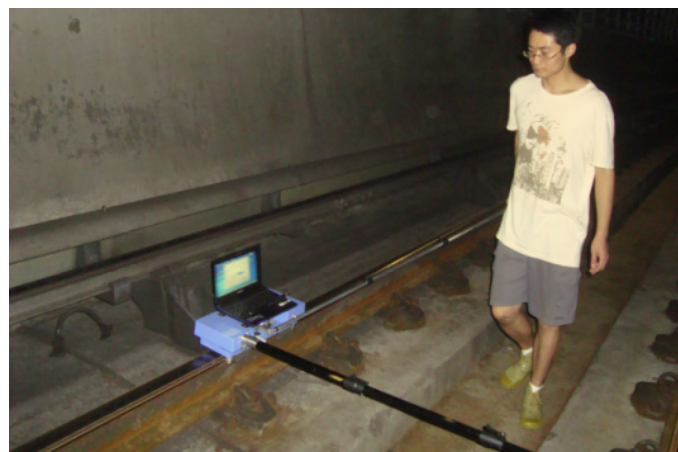

Fig. 3. Corrugation analysis trolley

The roughness data was captured from a measurement conducted in the section of DTVI2 track system in Beijing, in accordance with the model parameter. Raw data (Fig. 4) were provided as the input irregularities. The $1 / 3$ octave wavelength spectrum was shown in Fig. 5, indicted that the typical wavelength of the measured corrugated rail was $63 \mathrm{~mm}$.

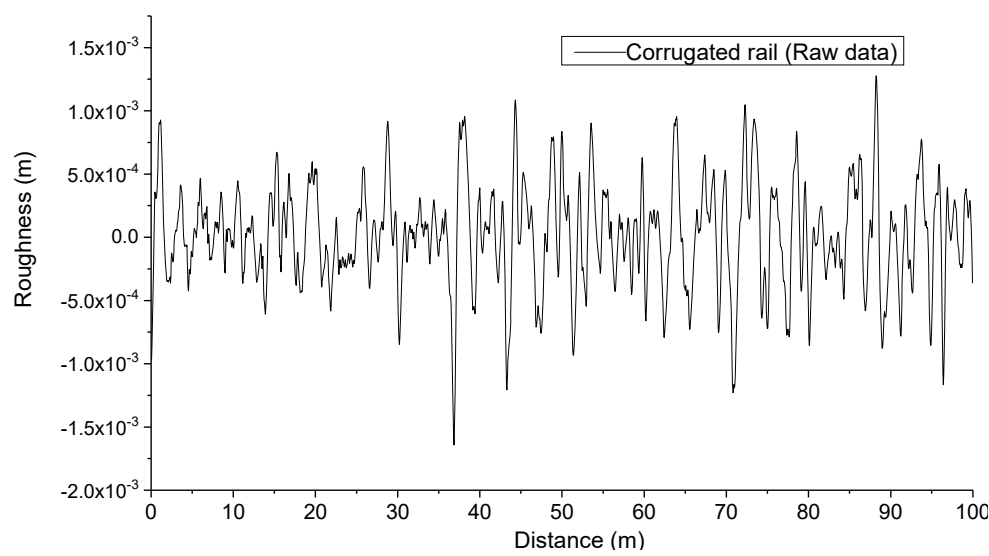

Fig. 4. Roughness of corrugated rail (Raw data)

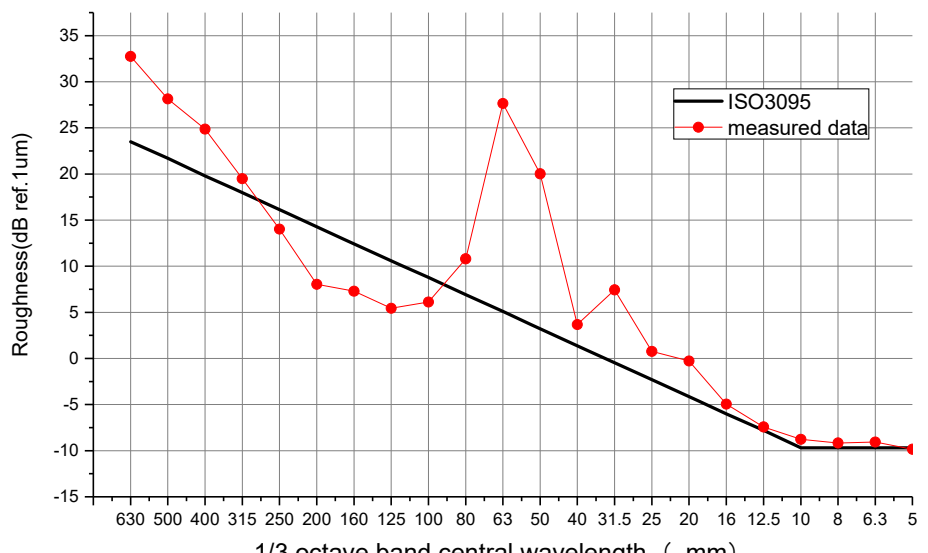

$1 / 3$ octave band central wavelength ( $\mathrm{mm}$ )

Fig. 5. 1/3 octave central wavelength 


\section{Calculation result}

The effect of rail roughness on the simulation modeling was discussed in this section, considering a train with perfect round wheels moved on different irregularities rail surface at the speed of $60 \mathrm{~km} / \mathrm{h}$, including perfect smooth rail, irregularities generated from a US PSD, measurement data from corrugated rails. As the rail vibration velocity always related to rolling noise, $1 / 3$ octave band vibration velocity response were recorded and analyzed.

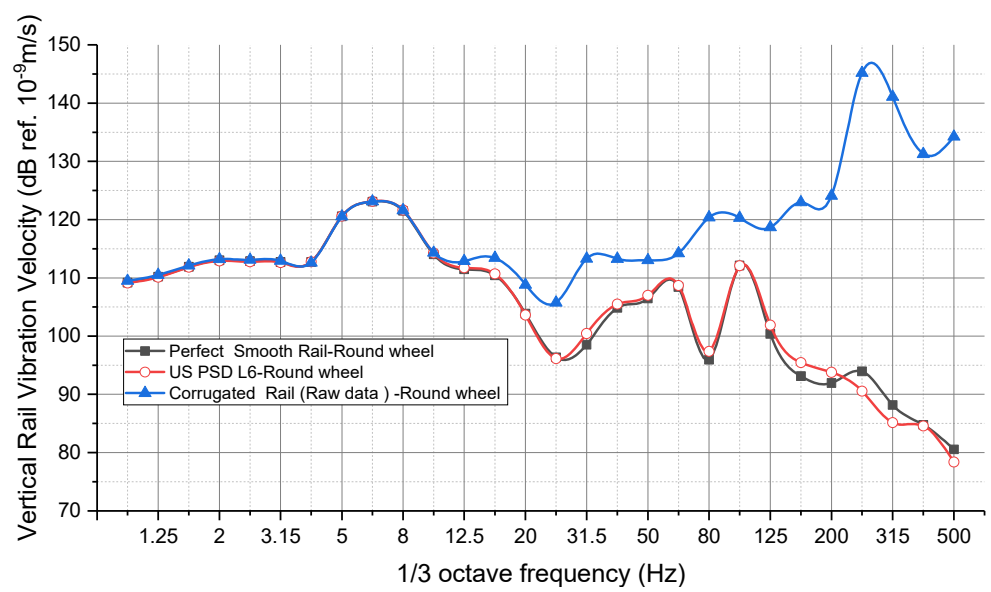

Fig. 6. Rail velocity vibration for different irregularities

From Fig. 6, it was clear that:

1) The curve of rail velocity vibration for using US PSD Lever 6 was very close to the irregularity of perfect smooth rail surface. It indicated the dynamic property of vehicle and track system plays the dominant role.

2) In low frequency range (less than $10 \mathrm{~Hz}$ ), measurement irregularity data of corrugated rail was not made difference from perfect smooth rail;

3) In the frequency from 10 to $63 \mathrm{~Hz}$, although the measurement irregularity data of corrugated rail raised the vibration velocity value, it still not alter the tendency of the curve that resulted by the dynamic property of vehicle and track system.

4) In high frequency that more than $63 \mathrm{~Hz}$, the effect of corrugated rail would be not neglected any more, especially at the band of $250 \mathrm{~Hz}$, corrugated rail plays the dominant role on the vibration which obviously related to the typical wavelength of $63 \mathrm{~mm}$ according to Eq. (2):

$f=\frac{V}{\lambda}=\frac{60 \mathrm{~km} / \mathrm{h}}{63 \mathrm{~mm}}=264 \mathrm{~Hz}$

\section{Conclusions}

Based on the above presented simulation results, interesting findings could be summarized as following:

1) It was demonstrated that the irregularity generated from US-PSD would not satisfy the requirement simulation on rolling noise and vibration generation in high frequency range;

2) Corrugated rail plays the dominant role on the vibration which obviously related to its typical wavelength.

\section{Acknowledgements}

This work was under the support of Beijing Natural Science Foundation (No. 3184047), 
Beijing Academy of Science and Technology Funds (No.OTP-2018-002) and Beijing Public Finance innovation project in 2018(PXM2018-178304_000007).

\section{References}

[1] Hougui Zhang, Zhou Ren, et al. Simulation on metro railway induced vibration. Part I: effect of out-of-round wheels. Vibroengineering Procedia, Vol. 29, https://doi.org/10.21595/vp.2019.21153, 2019.

[2] Jiang B. L., Ma M., Li M. H., et al. Experimental study of vibration characteristics of floating slab track in metro turnout zones. Proceedings of the Institution of Mechanical Engineers, Part F - Journal of Rail and Rapid Transit, Vol. 233, Issue 10, 2019, p. 1081-1096.

[3] Ma M., Liu W. N., Qian C. Y., et al. Study of the train-induced vibration impact on a historic Bell Tower above two spatial overlapping metro lines. Soil Dynamics and Earthquake Engineering, Vol. 81, 2016, p. 58-74.

[4] Ma M., Valéri Markine, Liu W. N., et al. Metro train-induced vibrations on historic buildings in Chengdu, China. Journal of Zhejiang University - Science A: Applied Physics and Engineering, Vol. 12, Issue 10, 2011, p. 782-793.

[5] Thompson D. J. Railway noise and vibration: mechanisms, modeling and means of control. Elsevier, Oxford, 2008.

[6] Lombaert G., Degrande G., François S., Thompson D. J. Ground-borne vibration due to railway traffic: a review of excitation mechanisms, prediction methods and mitigation measures. Notes on Numerical Fluid Mechanics and Multi-disciplinary Design, Vol. 126, 2015, p. 253-287.

[7] Zhang H. G., Liu W. N., Liu W. F., et al. Study on the cause and treatment of rail corrugation for Beijing metro. Wear, Vol. 317, Issues 1-2, 2014, p. 120-128.

[8] Grassie S. L. Rail corrugation: characteristics, causes and treatments. Proceedings of the Institution of Mechanical Engineers, Part F: Journal of Rail and Rapid Transit, Vol. 223, 2009, p. 581-595. 